\title{
Novel and Simple Synthesis Method for Submillimeter Long Vertically Aligned Single-Walled Carbon Nanotubes by No-Flow Alcohol Catalytic Chemical Vapor Deposition
}

Hisayoshi Oshima*, Yoshinobu Suzuki, Tomohiro Shimazu, and Shigeo Maruyama ${ }^{1}$

Research Laboratories, DENSO CORPORATION, 500-1 Minamiyama, Komenoki, Nisshin, Aichi 470-0111, Japan

${ }^{1}$ Department of Mechanical Engineering, The University of Tokyo, 7-3-1 Hongo, Bunkyo-ku, Tokyo 113-8656, Japan

Using a conventional thermal chemical vapor deposition (CVD) system, ethanol vapor was enclosed in a reactor, i.e., no flow, with $\mathrm{Co} / \mathrm{Mo}$ dip-coated quartz substrates to synthesize submillimeter long vertically aligned single-walled carbon nanotube (SWNT) films successfully. The no-flow CVD method yielded an increase in film thickness of up to $0.11 \mathrm{~mm}$ compared with the normal flowing gas method for $30 \mathrm{~min}$ of synthesis. The thermal decomposition of ethanol was investigated using Fourier transform infrared spectroscopy and quadrupole mass spectrometry. At CVD temperatures, ethanol decomposed mainly into ethylene, acetylene, acetaldehyde, and water. Some of these molecules could enhance SWNT growth.

KEYWORDS: carbon, nanotube, alcohol, CVD, decomposition, ethylene, water *E-mail address: hoosima@rlab.denso.co.jp 


\section{Introduction}

Since the discovery of carbon nanotubes in 1991, ${ }^{1)}$ they have been studied in various scientific and application fields. In particular, single-walled carbon nanotubes (SWNTs) have attracted great interest because of their unique properties. ${ }^{2}{ }^{2}$ SWNTs can be synthesized by arc-discharge, ${ }^{3)}$ laser ablation, ${ }^{4)}$ and chemical vapor deposition (CVD). ${ }^{5-15)}$ In CVD, carbon containing molecules, such as acetylene, ${ }^{5)}$ ethylene, ${ }^{15)}$ or methane ${ }^{6)}$ serve as carbon sources. Recently, alcohol has been employed as a carbon source $^{7,8)}$ and alcohol catalytic CVD (ACCVD) has become a popular CVD method for the growth of high-purity SWNT films, partly due to the low cost and easy handling of the nonhazardous CVD gas source. ${ }^{9-13)}$

Even though ACCVD is a powerful synthesis method, limited SWNT growth ${ }^{14)}$ is caused by catalyst poisoning, as in other CVD methods. We have reported that SWNTs are selectively grown by ACCVD because an $\mathrm{OH}$ radical produced by the decomposition of an alcohol molecule at the catalyst could remove amorphous carbon. ${ }^{7}$ Modifying this idea, Hata et al. ${ }^{15)}$ added a small amount of water for growth enhancement, where the water serves to remove amorphous carbon on catalysts. Actually, ethanol decomposes into water and ethylene when kept at the CVD temperature. ${ }^{16)}$ Hence, the decomposition of some percentage of ethanol is usually expected. Fortunately, ethylene is a carbon source for SWNT growth.

In this letter, we present ethanol-vapor-enclosed ACCVD, hereinafter called no-flow ACCVD, for accelerating ethanol decomposition during SWNT growth. An analysis of CVD gases is also presented to verify this concept. We found that the decomposition of ethanol could enhance the growth of SWNTs after the nucleation stage.

\section{Experiment Procedure}

For SWNT synthesis, a bimetallic Co-Mo catalyst was employed. The catalyst was formed on a quartz substrate as follows. A quartz substrate $\left(24 \times 12 \times 0.5 \mathrm{~mm}^{3}\right)$ was dipped in a $0.01 \mathrm{wt} \%$ Mo acetate solution, and then withdrawn at a rate of $2 \mathrm{~cm} / \mathrm{min}$. After annealing in air at $673 \mathrm{~K}$ for $5 \mathrm{~min}$, the substrate was dipped in a $0.01 \mathrm{wt} \% \mathrm{Co}$ acetate solution and withdrawn at the same rate. Finally, the substrate was again annealed in air at $673 \mathrm{~K}$ for $5 \mathrm{~min}$.

The experimental setup for SWNT growth is shown in Fig. 1. The substrate was inserted into a quartz tube, which was evacuated to $1 \times 10^{-4} \mathrm{~Pa}$ by a turbo-molecular pump. The tube was then heated up to the growth temperature $(1113 \mathrm{~K})$ under $40 \mathrm{kPa}$ of flowing $\mathrm{Ar} / \mathrm{H}_{2}\left(3 \% \mathrm{H}_{2}\right)$. When the growth temperature was reached after about $30 \mathrm{~min}$, 
the $\mathrm{Ar} / \mathrm{H}_{2}$ gas flow was stopped and the quartz tube was evacuated again until the pressure reached $1 \times 10^{-4} \mathrm{~Pa}$. The downstream valve was then closed, and ethanol vapor with or without $\mathrm{Ar} / \mathrm{H}_{2}$ gas was introduced into the tube. When some initial growth pressure was reached, the upstream valve was also closed. Initial growth pressure and growth time were varied from 1.3 to $2.7 \mathrm{kPa}$, and from 3 to $90 \mathrm{~min}$, respectively. The growth of SWNTs was terminated by opening the downstream valve.

CVD gas was analyzed by Fourier transform infrared spectroscopy (FT-IR; Otsuka electronics IG-1000) and quadrupole mass spectrometry (QMAS; Horiba M system). An FT-IR cell was inserted into the bypass line parallel to the exhaust line, as shown in Fig. 1. Prior to FT-IR, the cell was evacuated and the background spectrum was obtained. CVD gas was introduced into the cell by closing the downstream valve and opening the upstream valve of the cell for the measurement. The cell length was $10 \mathrm{~cm}$. Due to the difficulty in measuring water by FT-IR at low pressure, QMAS was employed for water measurement. The QMAS system was attached to the exhaust line, as shown in Fig. 1. SWNT films were observed by scanning electron microscopy (SEM; Hitachi S-5500), and their quality was examined by Raman scattering spectroscopy (JASCO NRS-3300).

\section{Results and Discussion}

Figure 2(a) shows a typical cross-sectional SEM image of a vertically aligned SWNT film grown by no-flow ACCVD. Film quality was confirmed by Raman scattering spectroscopy excited with a $488 \mathrm{~nm}$ laser from the side of the SWNT film. The $\mathrm{G}\left(1591 \mathrm{~cm}^{-1}\right) / \mathrm{D}\left(1342 \mathrm{~cm}^{-1}\right)$ ratio was approximately 50 , and radial breathing mode (RBM) peaks were clearly observed, as shown in Fig. 2(b). The predominant RBM peaks were at 158, 178, and $199 \mathrm{~cm}^{-1}$. The RBM spectra obtained from the lower, middle, and upper sections of the film showed similar profiles. The dependence of gas enclosure time, i.e., growth time, on film thickness is shown in Fig. 3. The thickness of the film grown by the traditional (constant-flow) ACCVD is also plotted. An increase in film thickness of approximately threefold was obtained using the no-flow ACCVD. The initial growth rates in the no-flow ACCVD were almost the same, as in the constant-flow ACCVD. Even with the use of the no-flow ACCVD, film thickness seemed to saturate after $30 \mathrm{~min}$. The enclosed gas pressure increased from 2.7 to 3.9 $\mathrm{kPa}$ during growth.

To investigate the gas enclosure effect, CVD gases were analyzed by FT-IR and QMAS. According to Herzler et al., ${ }^{16)}$ ethanol can thermally decompose at the CVD temperature. Thus, we investigated the thermal decomposition behavior of ethanol. Ethanol vapor was enclosed in a tube at $2.7 \mathrm{kPa}$ without any catalysts present and was 
heated to $1113 \mathrm{~K}$. The resulting ethanol vapor was held at this temperature between 3 and 15 min. After heating, the ethanol vapor was introduced into an FT-IR cell or the QMAS system, and the decomposed fragments were examined. The results show that about $70 \%$ of the ethanol decomposed with in $3 \mathrm{~min}$, generating ethylene, acetylene, acetaldehyde, methane, carbon monoxide, carbon dioxide, and water. This result indicates that the thermal decomposition of ethanol generates new carbon source molecules such as ethylene, as well as oxidative molecules such as water.

The time dependence of the amount of decomposed fragments was also analyzed by FT-IR. To discriminate thermally decomposed fragments from those decomposed via catalyst interaction, the spectral intensity obtained in the absence of a catalyst was subtracted from that obtained in the presence of a catalyst. The result showed that the amount of ethanol decreased with time, reaching zero after approximately $60 \mathrm{~min}$ as shown in Fig. 4. This time dependence curve has a shape similar to that of the growth curve shown in Fig. 3. Ethylene showed a similar behavior to ethanol. This result suggests that not only ethanol, but also ethylene is effectively used for SWNT growth. Other fragment molecules such as acetylene and carbon monoxide were difficult to analyze owing to their weak intensities.

The amount of water was determined qualitatively using QMAS instead of FT-IR. The integral intensity of the water signal $(\mathrm{m} / \mathrm{e}=18)$ decreased by approximately $50 \%$ when catalysts were present.

The results presented above suggest that the gas enclosure effect is induced by two processes. One is the enhancement of growth by generated hydrocarbons such as ethylene and acetylene. Even though $70 \%$ of the ethanol decomposes with in $3 \mathrm{~min}$, it should be noted that the growth rates for both no-flow and constant-flow ACCVDs were similar for about $10 \mathrm{~min}$. This result suggests that the nucleation stage is predominated by ethanol vapor; however, hydrocarbons may contribute to carbon growth only after the nucleation. Another process is catalyst activation by the generated water, as discussed in ref. 15. Although we discussed CVD phenomena by showing FT-IR and QMAS data, such data are not in situ measurements and thus some postreactions must be considered such as water adhesion on the inside of the exhaust gas line and gas decomposition on the QMAS filament. Further investigation is needed for quantitative discussion.

\section{Conclusions}

We have demonstrated a novel ACCVD method of obtaining submillimeter long vertically aligned SWNT films. Film thickness can be increased by enclosing ethanol 
gas inside the reactor tube during CVD. Enclosed ethanol vapor thermally decomposes into secondary hydrocarbons, which act as new CVD carbon sources, and water, which accelerates SWNT growth.

\section{References}

1) S. Iijima: Nature 354 (1991) 56.

2) R. Saito, G. Dresselhaus, and M.S. Dresselhaus: Physical Properties of Carbon Nanotubes (Imperial College Press, London, 1998).

3) C. Journet, W. K. Maser, P. Bernier, A. Loiseau, M. L. Chapelle, S. Lefrant, P. Deniard, R. Lee, and J. E. Fisher: Nature 388 (1997) 756.

4) A. Thess, R. Lee, P. Nikolaev, H. Dai, P. Petit, J. Robert, C. Xu, Y. H. Lee, S. G. Kim, A. G. Rinzler, D. T. Colbert, G. E. Scuseria, D. Tománek, J. E. Fischer, and R. E. Smalley: Science 273 (1996) 483.

5) Z. F. Ren, Z. P. Huang,. J. W. Xu, J. H. Wang, P. Bush, M. P. Siegel, and P. N. Provencio: Science 282 (1998) 1105.

6) J. Kong, H. T. Soh, A. M. Cassell, C. F. Quate, and H. Dai: Nature 395 (1998) 878.

7) S. Maruyama, R. Kojima, Y. Miyauchi, S. Chiashi and M. Kohno: Chem. Phys. Lett. 360 (2002) 229.

8) Y. Murakami, S. Chiashi, Y. Miyauchi, M. Hu, M. Ogura, T. Okubo, and S. Maruyama: Chem. Phys. Lett. 385 (2004) 298.

9) L. Huang, X. Cui, B. White, and S. P. Obrien: Phys. Chem. B 108 (2004) 16451.

10) Y. Zhao, K. Seko, and Y. Saito: Jpn. J. Appl. Phys. 45 (2006) 6508.

11) L. X. Zheng, M. J. O'Connell, S. K. Doorn, X. Z. Liao, Y. H. Zhao, E. A. Akhadov, M. A. Hoffbauer, B. J. Roop, Q. X. Jia, R. C. Dye, D. E. Peterson, S. M. Huang, J. Liu, and Y. T. Zhu: Nat. Mater. 3 (2004) 673.

12) Y. Fujiwara, K. Maehashi, Y. Ohno, K. Inoue, and K. Matsumoto: Jpn. J. Appl. Phys. 44 (2005) 1581.

13) S. Noda, H. Sugime, T. Osawa, Y. Tsuji, S. Chiashi, Y. Murakami and S. Maruyama: Carbon 44 (2006) 1414.

14) S. Maruyama, E. Einarsson, Y. Murakami, and T. Edamura: Chem. Phys. Lett. 403 (2005) 320.

15) K. Hata, D. Futaba, K. Mizuno, T. Namai, M. Yumura, and S. Iijima: Science 306 (2004) 1362.

16) J. Herzler, W. Tsang, and J. A. Manion: J. Phys. Chem. 101 (1997) 5500. 


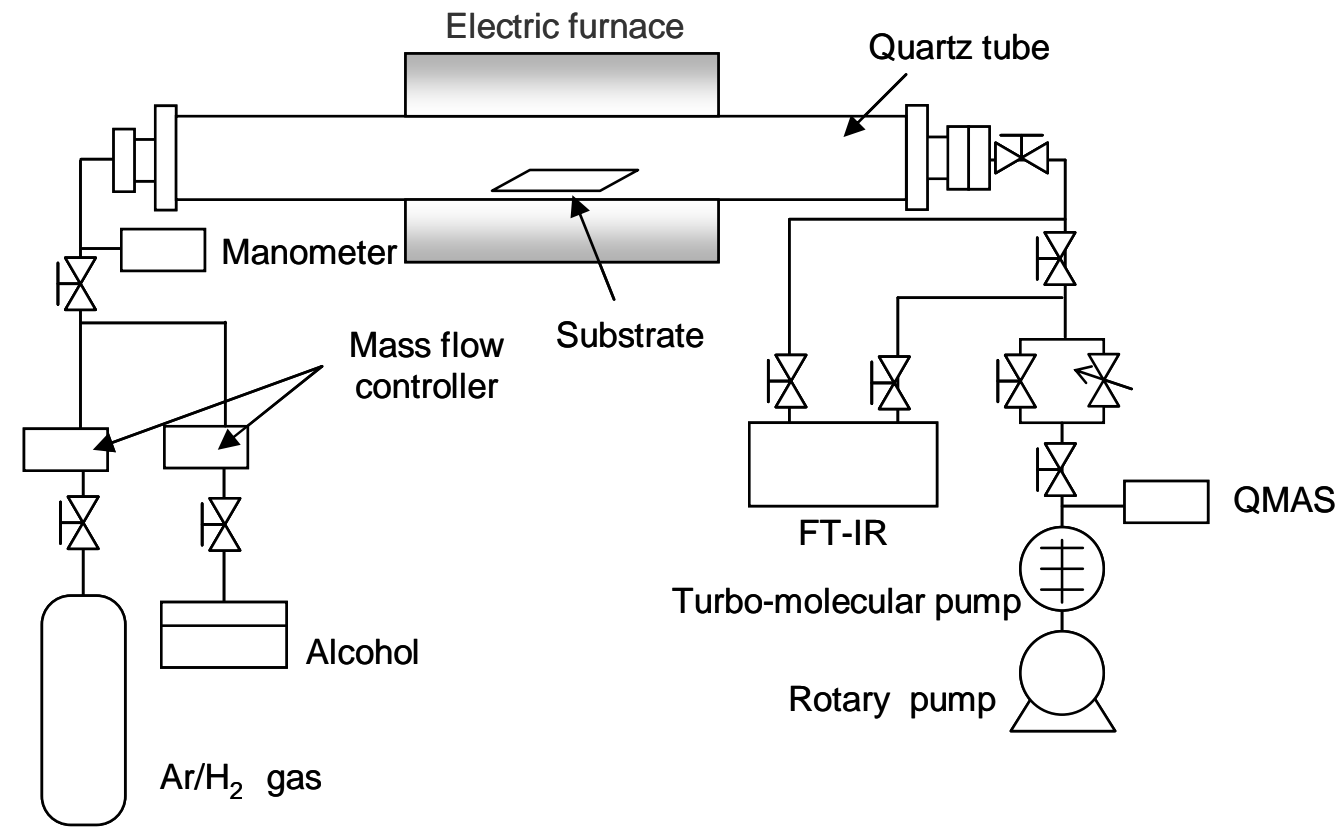

Figure 1. Schematic diagram of experimental apparatus for SWNT growth and CVD gas analysis.

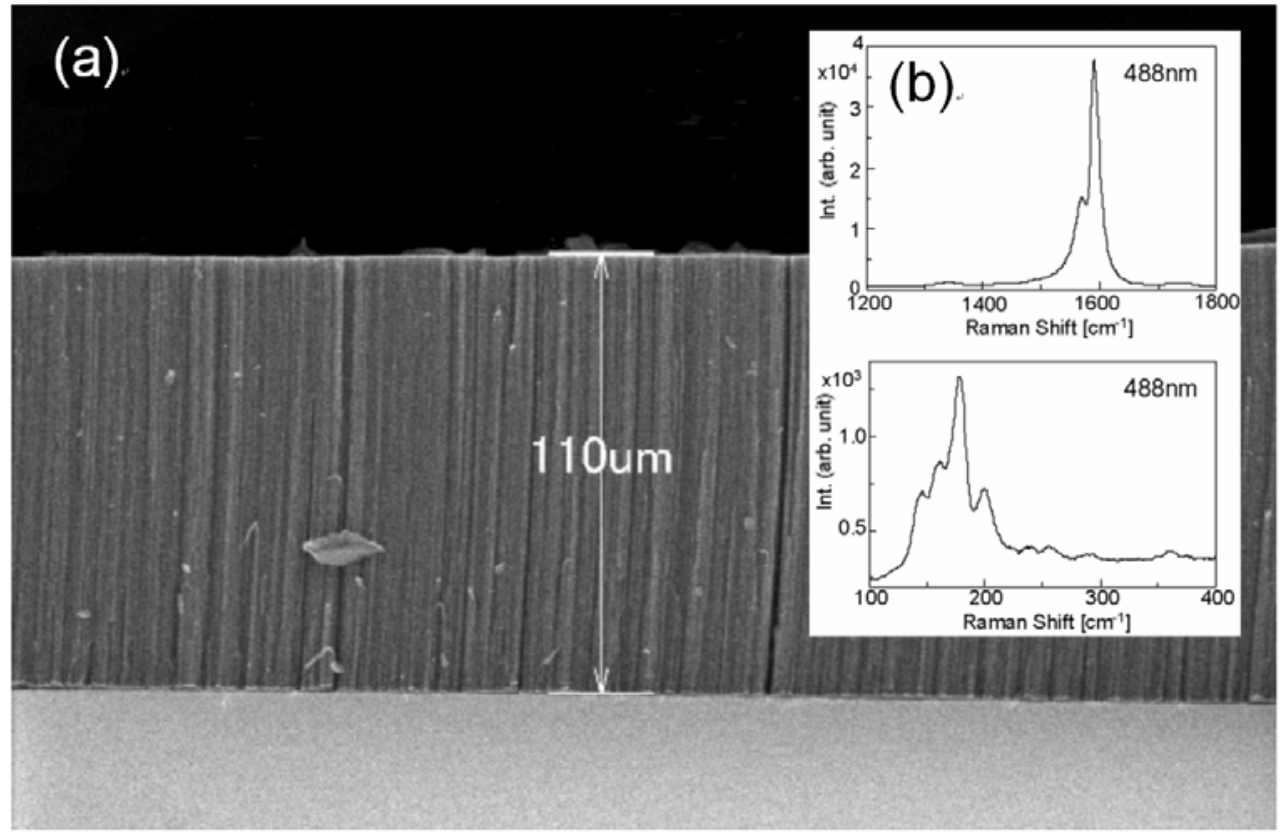

Figure 2. Typical cross-sectional SEM image of vertically aligned SWNT film obtained by no-flow ACCVD. Growth conditions: initial ethanol pressure, $2.7 \mathrm{kPa}$; growth temperature, $1113 \mathrm{~K}$; and growth time, $30 \mathrm{~min}$. 


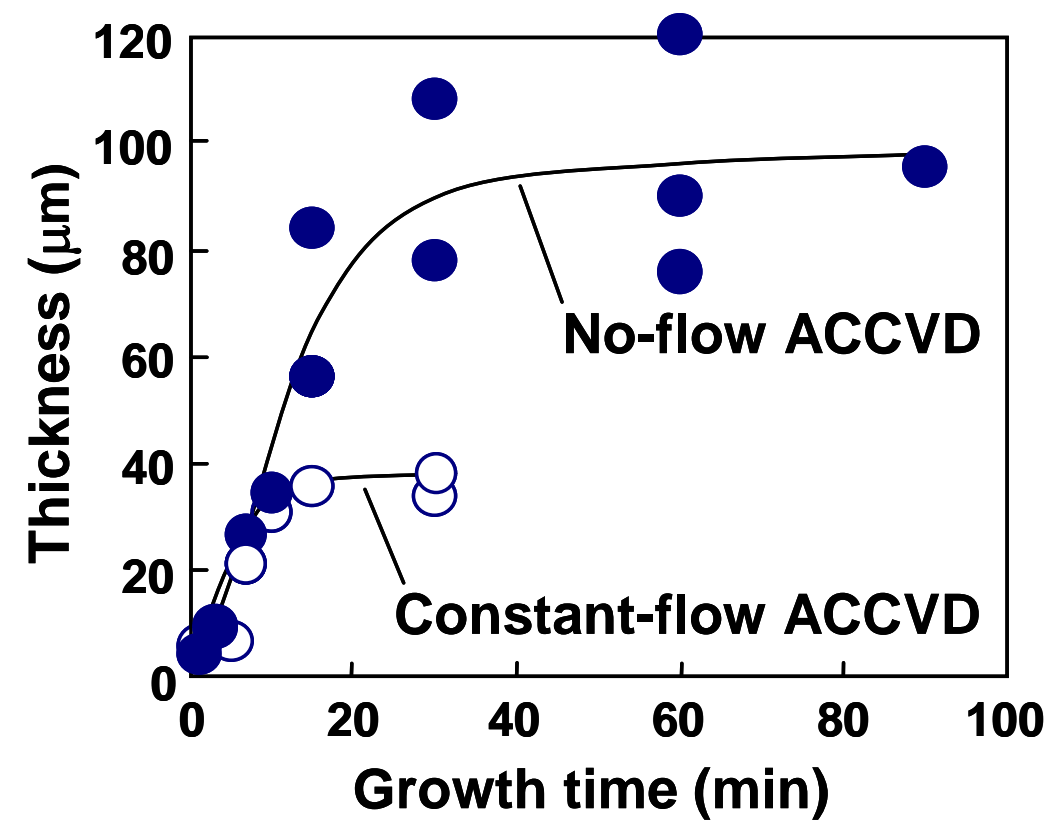

Figure 3. SWNT film thickness as function of growth time. No-flow ACCVD conditions: initial pressure of $2.7 \mathrm{kPa}$ at $1113 \mathrm{~K}$. Constant-flow ACCVD conditions: gas pressure of $1.3 \mathrm{kPa}$ at $1113 \mathrm{~K}$ and gas flow rates of $20 \mathrm{sccm} \mathrm{Ar}$, and $20 \mathrm{sccm}$ ethanol.

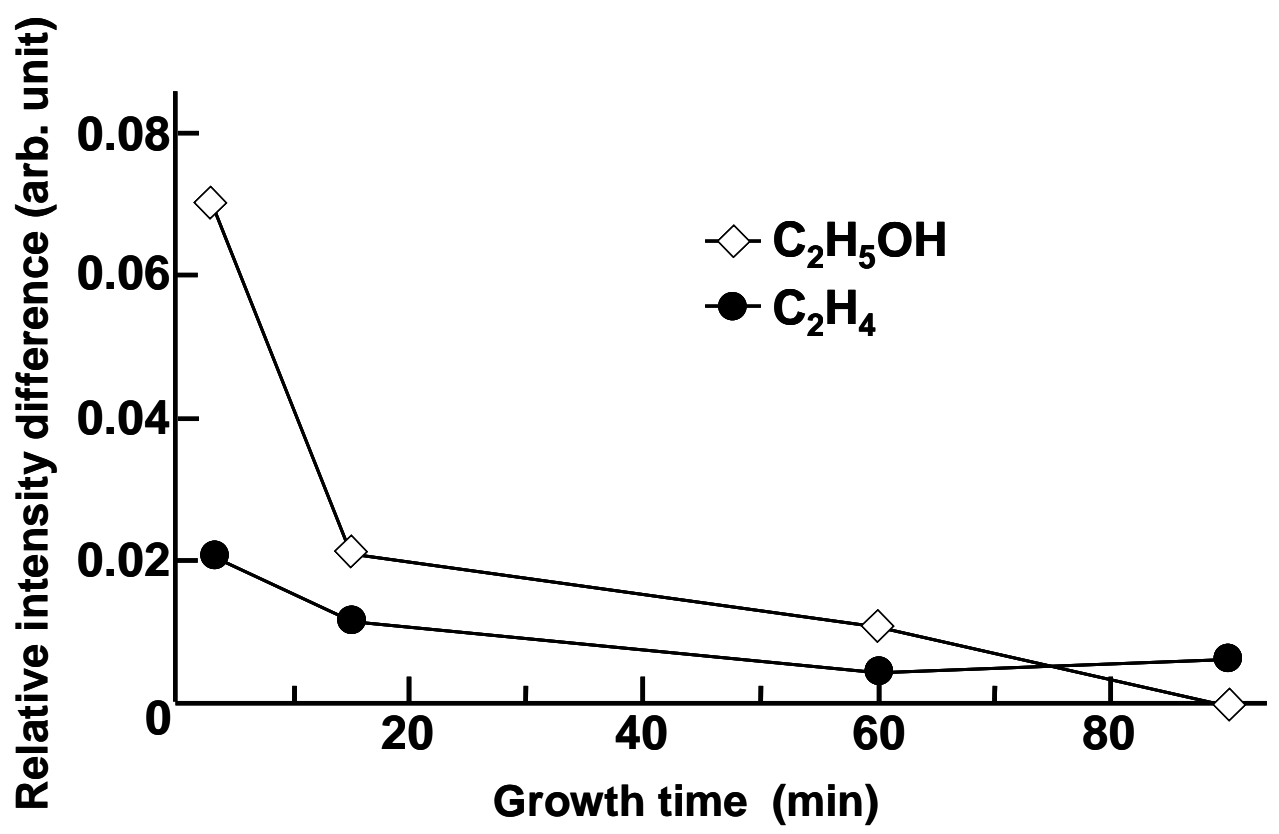

Figure 4. Relative FT-IR intensity difference between ethanol and ethylene as function of growth time. Each intensity is normalized by the intensity of ethanol at $2.7 \mathrm{kPa}$ at RT. 